\title{
Successful hybrid NOTES resection of early gastric cancer in a patient with concomitant advanced colon cancer
}

NOTES (natural orifice transluminal endoscopic surgery) is currently of greatest interest to endoscopists and laparoscopic surgeons [1-3]. Early gastric cancer (EGC) is generally managed with endoscopic submucosal resection (ESD) if indicated. We present a case of EGC removed by hybrid NOTES, with a concomitant colon cancer resected via laparoscopic colectomy.

A 62-year-old man was diagnosed with simultaneous gastric and colonic cancer. The gastric cancer was an EGC in the form of a moderately differentiated adenocarcinoma on the upper body; the mass in the ascending colon was also moderately differentiated adenocarcinoma ( $\bullet$ Fig. 1). Computed tomography and positron emission tomography showed no definite evidence of metastasis. Although total gastrectomy with right colectomy was the treatment of choice, the patient was concerned about his expected quality of life after the surgical resection. ESD of the EGC was also considered, but this was not suitable even on the basis of an expanded indication [4]. We therefore decided to perform hybrid NOTES for gastric adenocarcinoma and laparoscopy-assisted colectomy.

After successful removal of the colon cancer by the colorectal surgeon (J. K.) using a standardized laparoscopic technique, the endoscopist (B. K.) used an improved insulated-tip (IT2) knife and endoscopic papillotome to cut around the EGC for a fullthickness incision. The stomach was artificially perforated and collapsed, and a surgeon (S. S. P.) helped by holding back the shrunken stomach. The lesion was cut around for about two-thirds of the total diameter, and laparoscopic removal was completed via a wedge resection with stapling ( $\bullet$ Fig. 2). Pathologically, the gastric lesion was a poorly differentiated tubular adenocarcinoma (type IIb + IIc) invading the lamina propria. The colon cancer was diagnosed as a moderately differentiated adenocarcinoma with three positive lymph nodes. The resection margins of both cancers were free of carcinoma. Endoscopic follow-up and a CT scan taken after 4 months revealed no distinct recurrence of either lesion.

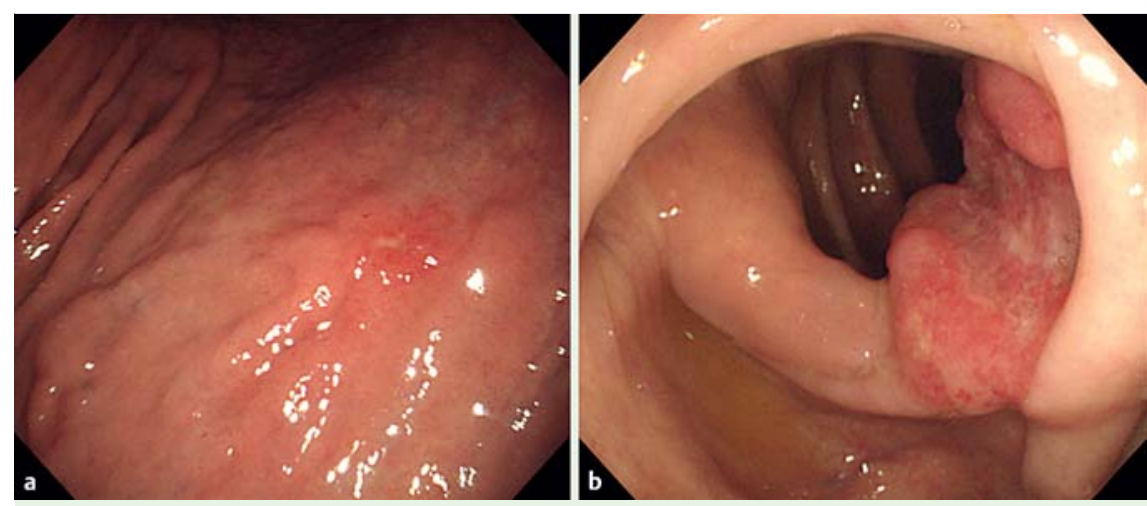

Fig. 1 a The shallow ulcerative lesion on the posterior wall of the upper body was diagnosed as adenocarcinoma. $\mathbf{b}$ The ulcerofungating mass noted on the ascending colon was also confirmed as an adenocarcinoma.
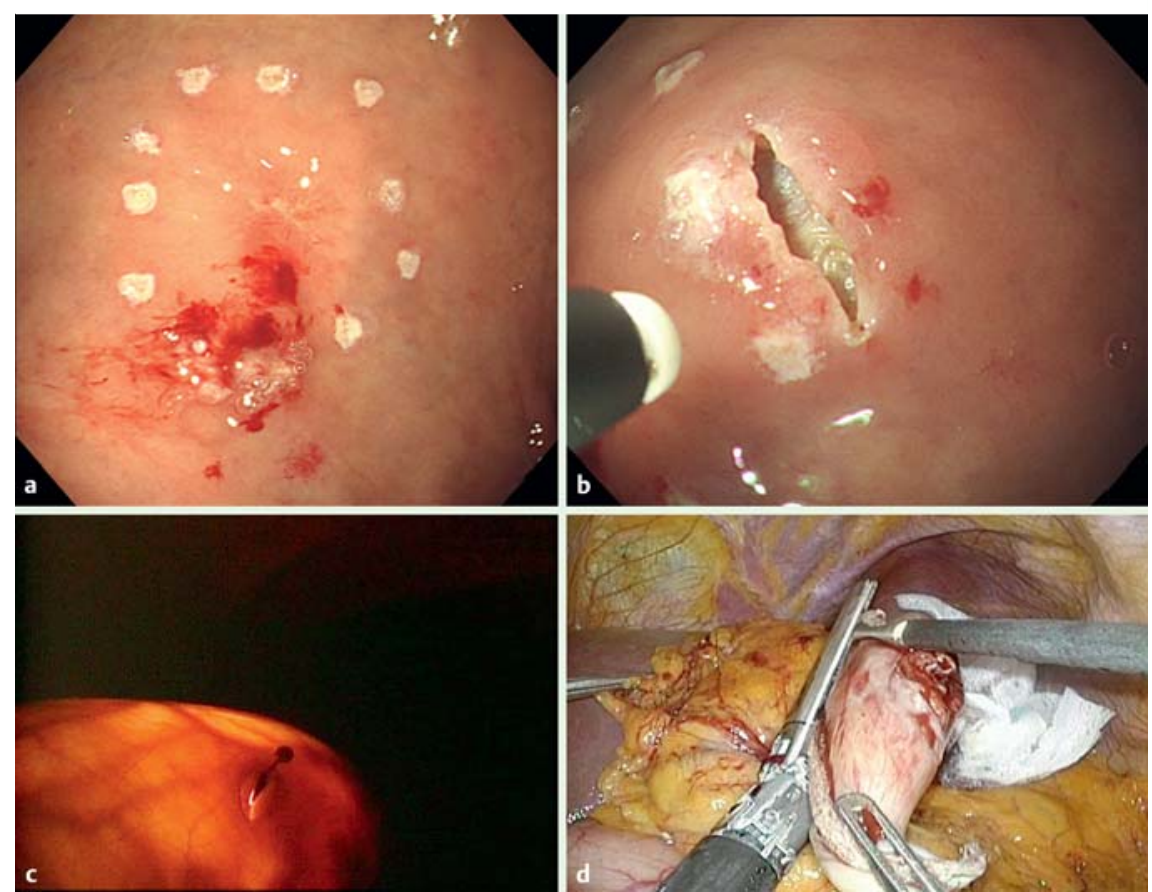

Fig. 2 a, b Endoscopic and laparoscopic findings during hybrid NOTES. a A needle-knife was used to make circumferential surface marks around the gastric cancer, followed by $(\mathbf{b}, \mathbf{c})$ full-thickness cutting around the lesion using an IT2 knife. $\mathbf{d}$ Laparoscopic assistance completed the hybrid NOTES procedure with a wedge resection.

Current NOTES researchers who still have access to only a handful of pre-existing equipment without any innovative new devices will benefit from the possibility of performing hybrid NOTES. In an institution with an experienced laparoscopic surgeon and also a skillful endoscopist, hybrid NOTES is a reasonable choice for patients requiring organ preservation. It will also function as a crucial makeshift bridge for crossing over to authentic NOTES in the near future.

Endoscopy_UCTN_Code_TTT_1AO_2AG 
S. Park ${ }^{1}$, H. J. Chun ${ }^{1}$, B. Keum ${ }^{1}$, Y. S. Seo ${ }^{1}$, Y. T. Jeen ${ }^{1}$, S. H. Um ${ }^{1}$, C. D. Kim", H. S. Ryu ${ }^{1}$, S.-S. Park ${ }^{2}$, J. Kim²

1 Department of Internal Medicine, Institute of Digestive Disease and Nutrition, Korea University College of Medicine, Seoul, Korea

2 Department of Surgery, Korea University College of Medicine, Seoul, Korea

\section{References}

1 Kantsevoy S, Magee C, Vaughn Cet al. Flexible transgastric peritoneoscopy: a novel approach to diagnostic and therapeutic interventions in the peritoneal cavity. Gastrointest Endosc 2004; 60: 114-117

$2 \mathrm{Kim}$ Y, Kim C, Chun H. Natural orifice transluminal endoscopic surgery (NOTES) [in Korean]. Korean J Gastroenterol 2008; 51: 154-158

3 Rösch T. Who votes for NOTES? Gut 2008; 57: $1481-1486$

4 Gotoda T, Yanagisawa A, Sasako M et al. Incidence of lymph node metastasis from early gastric cancer: estimation with a large number of cases at two large centers. Gastric Cancer 2000; 3: 219-225
Bibliography

DOI $10.1055 / \mathrm{s}-0029-1215255$

Endoscopy 2010; 42: E1-E2

(c) Georg Thieme Verlag KG Stuttgart · New York . ISSN 0013-726X

\section{Corresponding author}

\section{H. J. Chun, MD, PhD}

Department of Internal Medicine Institute of Digestive Disease and Nutrition Korea University College of Medicine 126-1, 5-Ga, Anam-Dong

Seongbuk-Gu

Seoul 136-705

Korea

Fax: +82-2-9531943

drchunhj@chol.com 